\title{
Occurrence of carcinogenic aldehydes in alcoholic beverages from Asia
}

\author{
Dirk W. Lachenmeier ${ }^{1,5}$, Yulia B. Monakhova ${ }^{1,2}$, Jürgen Rehm ${ }^{3,4,5}$, Thomas Kuballa ${ }^{1}$, and Irene Straub ${ }^{1}$ \\ ${ }^{1}$ Chemisches und Veterinäruntersuchungsamt (CVUA) Karlsruhe, Karlsruhe, Germany \\ ${ }^{2}$ Department of Chemistry, Saratov State University, Saratov, Russia \\ ${ }^{3}$ Centre for Addiction and Mental Health (CAMH), Toronto, Canada \\ ${ }^{4}$ Dalla Lana School of Public Health, University of Toronto, Toronto, Canada \\ ${ }^{5}$ Epidemiological Research Unit, Institute for Clinical Psychology and Psychotherapy, Dresden, Germany
}

\begin{abstract}
Aims: Formaldehyde and acetaldehyde associated with alcohol consumption are both carcinogenic to humans (WHO IARC group 1 carcinogens). While several surveys exist on occurrence and exposure of the two aldehydes in alcoholic beverages from Europe and the Americas, we aimed to study domestic products of Asian countries.

Methods: Alcohol products from Asian countries (China, Korea, Japan and Thailand), including traditionally fermented beverages (sake, rice wine) as well as distilled spirits, were collected $(n=54)$ and chemically analyzed for alcohol quality.

Findings: In 9 of 39 samples (23\%) analyzed for formaldehyde, its concentration was higher than the WHO IPCS tolerable concentration of 2.6 $\mathrm{mg} / \mathrm{L}$. Three samples contained more than $10 \mathrm{mg} / \mathrm{L}$ with a maximum concentration of $14.6 \mathrm{mg} / \mathrm{L}$. In 15 of 54 samples (28\%) analyzed for acetaldehyde, the concentration exceeded $50 \mathrm{~g} / \mathrm{hL}$ of pure alcohol (pa). The maximum concentration of acetaldehyde was $127 \mathrm{~g} / \mathrm{hL}$ pa. The incidence of the aldehydes, especially of formaldehyde, in the Asian sample was considerably higher than what was found in surveys of European-style alcoholic beverages.

Conclusions: While acetaldehyde is a natural constituent of alcoholic beverages and is also produced during ethanol metabolism in humans, the presence of formaldehyde is unusual and raises questions about its origin. A likely explanation is that it is used as a disinfectant during production - a questionable practice, not only because of the resultant residues in the beverages, but also because of the risks to production workers of occupational exposure. Detailed exposure assessment using larger samples is needed to characterize the risk arising from the aldehydes for the alcohol-drinking population.
\end{abstract}

Alcohol consumption in Asian countries is markedly lower than the global average, but alcohol is nevertheless an important risk factor for many disease categories in these countries (Rehm et al., 2009; World Health Organization [WHO], 2011). In Asia, the total (recorded and unrecorded) adult (15 years of age and over) per capita consumption is highest in the Republic of Korea (14.8 litres) and Kazakhstan (11.0 litres) (WHO, 2012). For China, Japan and Thailand, the per capita alcohol consumption levels are also above average: 5.9, 8.0 and 7.0 litres, respectively (WHO, 2012).

The production of alcoholic beverages has a very long history in Asian countries, particularly in China, and is still an important industry today. The most widely consumed alcoholic beverages in Asia are spirits made of rice or grain (WHO, 2011). Traditional alcoholic beverages include sake (a brewed rice wine), yellow wine, fruit wine and flavored wine (WHO, 2011).

There is a general lack of information concerning the composition of Asian alcoholic beverages in the scientific literature, with only limited overviews from China, Nepal, Japan or Vietnam available (see review in Lachenmeier, Anh, Popova, \& Rehm, 2009). Currently, there are also only limited data available on health-relevant constituents and contaminants, such as aldehydes or higher alcohols, for alcohol products from Asian countries. The largest worldwide survey available so far, which examined about 500 products, found higher formaldehyde concentrations in some samples from Asia than in products from Europe (Jendral, Monakhova, \& Lachenmeier, 2011).

Correspondence: D. W. Lachenmeier, Chemisches und Veterinäruntersuchungsamt (CVUA) Karlsruhe, Weissenburger Strasse 3, 76187 Karlsruhe, Germany Telephone: +49-721-926-5434. Fax: +49-721-925-5539. E-mail: Lachenmeier@web.de

Financial support: This work was supported by a combined grant (No. 2.2.2.3/9033) from the DAAD (German Academic Exchange Service) and the Russian Ministry of Science and Education, to Yulia B Monakhova. Support to CAMH for the salaries of scientists and infrastructure has been provided by the Ontario Ministry of Health and Long Term Care. The contents of this paper are solely the responsibility of the authors and do not necessarily represent the official views of the Ministry of Health and Long Term Care or other funders.

Declaration of interest: None.

Keywords: alcoholic beverages; Asia; acetaldehyde; formaldehyde; quality control; alcohol-related disorders 
In the present study, we evaluated alcohol quality in products produced in Asian countries, with special emphasis on toxic aldehydes (acetaldehyde and formaldehyde). Formaldehyde has been causally related to increased risks of leukemia and nasopharyngeal cancer in humans (Baan et al., 2009), while the principal sites of acetaldehyde carcinogenicity are esophagus, head and neck (Secretan et al., 2009). Both compounds have been classified as "carcinogenic to humans" (group 1) by the International Agency for Research on Cancer (IARC) (Baan et al., 2009; Secretan et al., 2009).

\section{Method}

\section{Collection of Samples}

Fifty-four $(N=54)$ samples of alcohol products from four Asian countries-China $(n=38)$, Korea $(n=2)$, Japan $(n=$ 9 ), and Thailand ( $n=5)$-were collected and subjected to chemical analyses (see Table 1 for details on samples and parameters). These particular countries were chosen for availability in a convenience sample in Germany and Canada. The sampling strategy was to collect different types of alcohol, ranging from sake and distilled spirits to cooking wine. Forty-three alcohol samples imported from these Asian countries were purchased from different shops, Asian restaurants and markets in Baden-Württemberg, Germany. A total of 11 samples were collected in Toronto, Canada, at the government-run liquor shop (Liquor Control Board of Ontario) and in Chinese restaurants. Table 1 presents the origins and types of all samples.

\section{Analytical Procedure}

The parameters detailed in Table 1 were analyzed using validated reference methodologies, including Fourier transform infrared spectroscopy (alcoholic strength) and gas chromatography (volatiles including acetaldehyde). The methodology was previously published in detail (Lachenmeier et al., 2011). Formaldehyde was analyzed according to Jendral, Monakhova, and Lachenmeier (2011), using spectrophotometry, and the results were confirmed by $400 \mathrm{MHz}{ }^{1} \mathrm{H}$ nuclear magnetic resonance spectroscopy. The results are expressed in the same units in which the international limits are provided. Volatile compounds contained in the samples are expressed by the unit "g/hL of pure alcohol" (i.e., the concentrations are standardized in relation to alcoholic strength). For clarity, we use the abbreviation " $\mathrm{g} / \mathrm{hL}$ pa." The results for formaldehyde are presented as "mg/L." Alcoholic strength is indicated as "\% vol.” (percent by volume).

\section{Toxicological Evaluation}

The toxicological evaluation of many compounds in alcoholic beverages is problematic, since even for the most common compounds, such as higher alcohols, no international maximum limits have been established. This paper therefore uses the criteria established by the Alcohol Public Health Research Alliance (AMPHORA) project, which are generally based on Acceptable Daily Intakes (ADI) for foods, with the assumption of daily exposure over a lifetime. A detailed rationale for the limits proposed by AMPHORA was previously published (Lachenmeier \& Monakhova, 2011). For formaldehyde, a tolerable concentration (TC) of $2.6 \mathrm{mg} / \mathrm{L}$ in ingested products has been suggested by the WHO International Program on Chemical Safety (IPCS), based on animal experiments (IPCS, 2002).

\section{Results}

Table 1 presents the results of the analysis of all samples. The actual alcoholic strengths of the samples ranged from $11.1 \%$ vol. (rice wine) to $61.9 \%$ vol. (grain spirit). The highest alcoholic strengths were found in grain spirits (typically around 65\% vol.), while wines had alcoholic strengths between $11 \%$ and $20 \%$ vol. Methanol was detected in concentrations ranging from not detectable to $419 \mathrm{~g} / \mathrm{hL}$ pa. Generally, the methanol levels were below $30 \mathrm{~g} / \mathrm{hL}$ pa, which is comparable to grain spirits from other countries. Levels of higher alcohols varied from not detectable to $150 \mathrm{~g} / \mathrm{hL}$ pa., and 2-phenyl ethanol was detected in 25 samples $(0.7 \mathrm{~g} / \mathrm{hL}$ pa- $23 \mathrm{~g} / \mathrm{hL}$ pa $)$. A high variability was found for benzaldehyde and ethyl acetate. None of the samples contained methyl acetate.

Acetaldehyde was found in $88.9 \%(n=48)$ of the investigated samples, and $28.7 \%(n=15)$ of samples showed concentrations above the AMPHORA limit (50 $\mathrm{g} / \mathrm{hL} \mathrm{pa).} \mathrm{Formaldehyde} \mathrm{was} \mathrm{found} \mathrm{in} 14$ of 39 beverages, in a concentration range of 0.2 to $14.6 \mathrm{mg} / \mathrm{L}$. Nine of these beverages had a higher formaldehyde content than the WHO IPCS tolerable concentration $(2.6 \mathrm{mg} / \mathrm{l})$.

\section{Discussion}

In general, the volatile composition of the analyzed products was within acceptable ranges, with the exception of the aldehydes formaldehyde and acetaldehyde in several of the products.

The average formaldehyde concentration of all analyzed products was $2.3 \mathrm{mg} / \mathrm{L}$, which is close to the WHO IPCS limit of $2.6 \mathrm{mg} / \mathrm{L}$. Furthermore, a high percentage of beverages (23\%) exceeded this limit. In comparison, this prevalence was only 9 out of 508 samples (2\%) in a previous survey of international alcoholic beverages (Jendral et al., 2011).

Unlike acetaldehyde (see below), formaldehyde was found not only in spirits but also in other beverages (for example, in Korean Charm soju and Japanese sake). It is also notable that four of the five samples from Thailand exceeded the WHO IPCS limit. The most troubling results in our study were the samples J03 and T02, with formaldehyde concentrations above $14 \mathrm{mg} / \mathrm{L}$. 


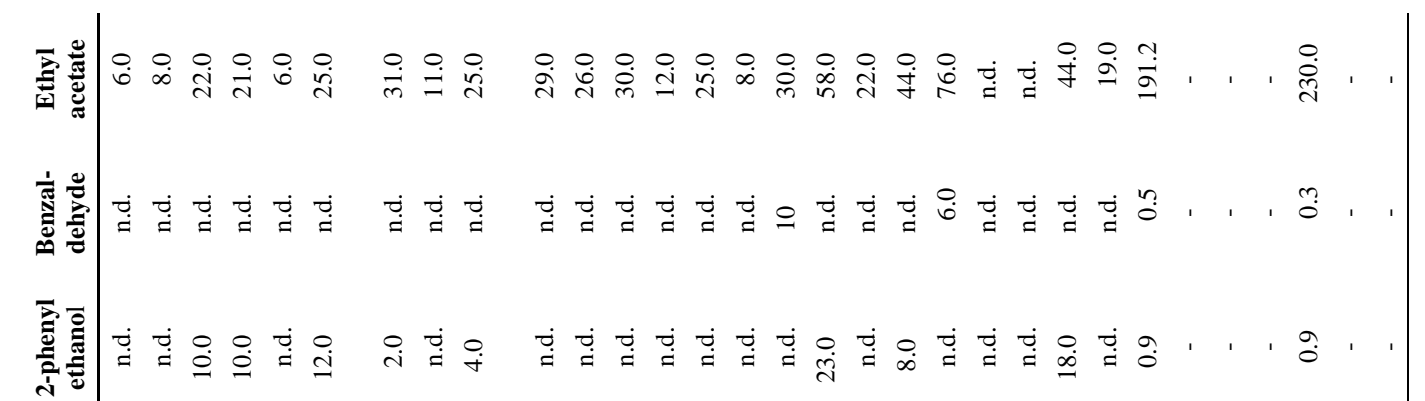

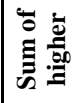

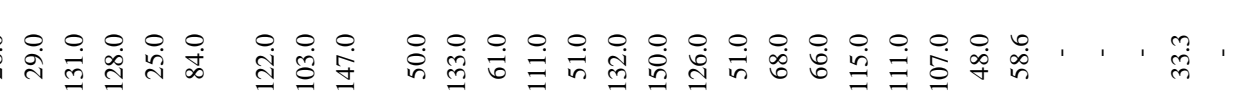

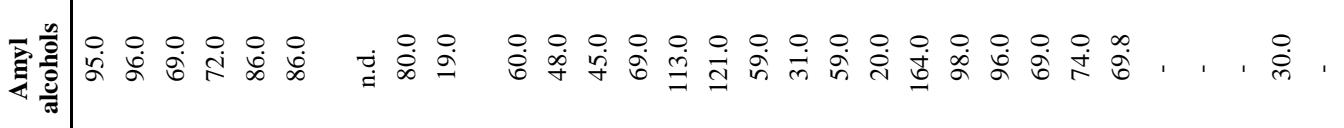

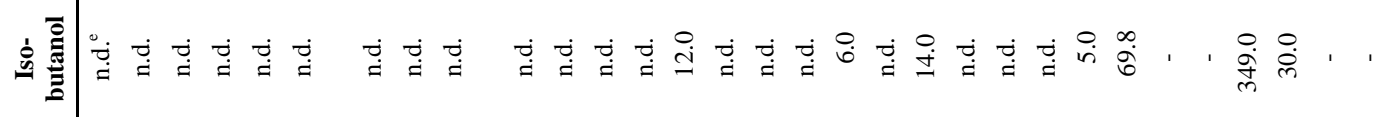

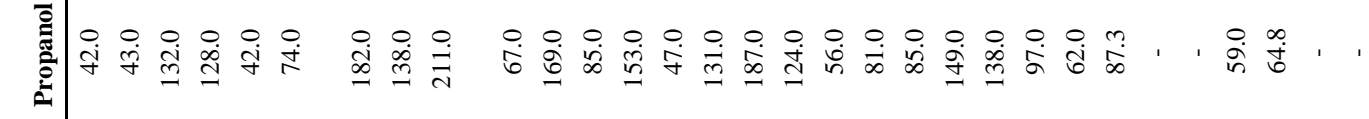

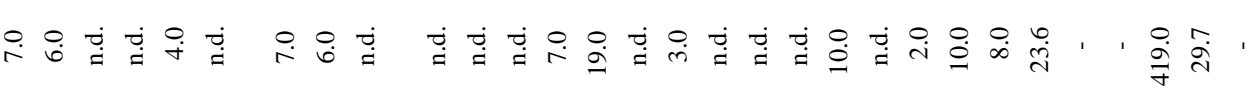

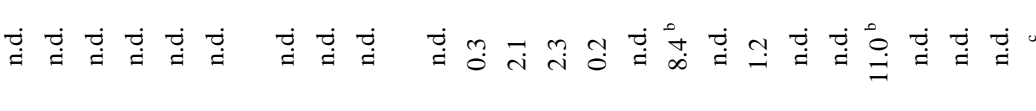

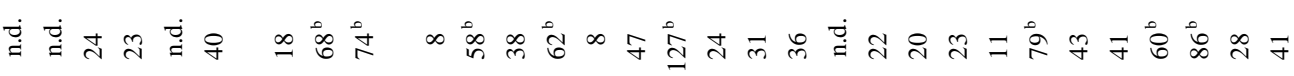
$\because \frac{0}{3}$

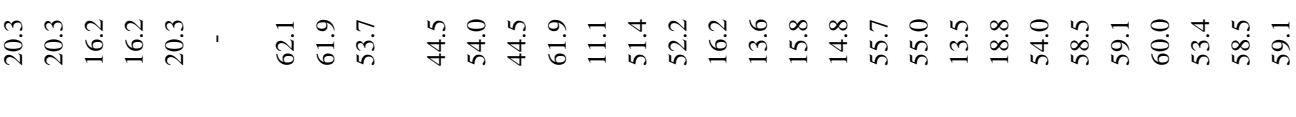




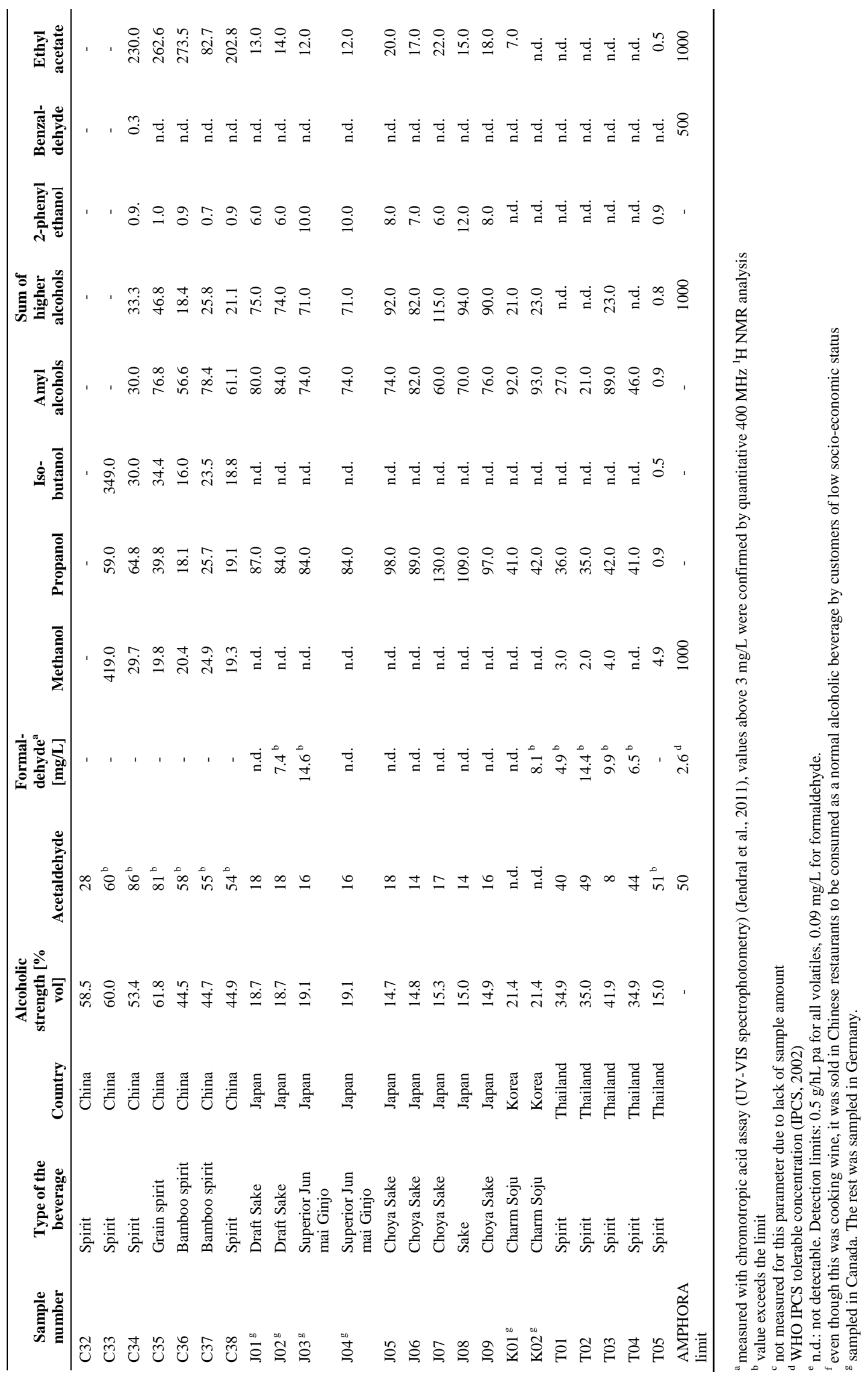


According to estimations from Feron et al. (1991), the formaldehyde intake from food ranges between 1.5 and 14 $\mathrm{mg} /$ person/day, which already may reach the reference dose for chronic oral exposure (RfD) of $0.2 \mathrm{mg} / \mathrm{kg}$ bodyweight/day (approximately $12 \mathrm{mg} /$ day for a 60-kg adult) postulated by the United States Environmental Protection Agency (US EPA) (1998). The consumption of formaldehyde-contaminated alcoholic beverages could considerably increase this exposure, so that the total exposure would likely exceed the mentioned threshold. Therefore, it would seem to be a prudent public health policy measure to limit human formaldehyde exposure from alcoholic beverages. As a first step towards this action, the cause of the formaldehyde contamination must be determined. It seems unlikely that the residues derive naturally from methanol oxidation, as the methanol levels are quite low, and even in alcoholic beverages with 10 -fold higher methanol concentrations we have never observed such high formaldehyde levels. A hypothesis is that formaldehyde-containing or formaldehyde-releasing disinfectants have been used, possibly to clean equipment or to suppress unwanted microorganisms during fermentation. Such practices are clearly questionable due to the occupational risk they create for production workers, and may pose additional risks if it is not ensured (e.g., by rinsing off disinfectant residues) that the final products are formaldehyde free.

The average acetaldehyde residue of the analyzed Asian beverages was $35 \mathrm{~g} / \mathrm{hL}$ pa. Remarkably, the AMPHORA limit was exceeded in all sampled spirits (average acetaldehyde concentration of about $50 \mathrm{~g} / \mathrm{hL}$ pa, with maximum value of $127 \mathrm{~g} / \mathrm{hL}$ pa [sample C16]). The Asian spirits thus showed large deviations from the typical acetaldehyde values found in international spirits (e.g., the averages for vodka, rum and brandy are $0.7,4$, and $20 \mathrm{~g} / \mathrm{hL}$ pa, respectively (Lachenmeier \& Sohnius, 2008)). This finding confirms our previous results in a study of a more limited range of samples from China, which also showed relatively high concentrations of acetaldehyde $(62 \mathrm{~g} / \mathrm{hL}$ pa on average (Lachenmeier \& Sohnius, 2008)).

During the production of spirits, acetaldehyde may be formed not only as a product of alcoholic fermentation by Saccharomyces yeast, but also as a metabolite of microorganisms like lactic acid or acetic acid bacteria, and through the coupled auto-oxidation of ethanol and phenolic compounds (Liu \& Pilone, 2000). It is important to note that the Asian samples are not unique for such high acetaldehyde contamination, as high acetaldehyde values have been detected, in single cases, in spirits from low to middle income countries (see, for example Kanteres, Rehm, \& Lachenmeier, 2009).

Very high concentrations of acetaldehyde in alcoholic beverages - such as those observed in the spirits from Asia_can cause salivary acetaldehyde concentration levels considered potentially carcinogenic (Lachenmeier \& Monakhova, 2011). Therefore, although acetaldehyde cannot be completely avoided, due to its natural occurrence (e.g., see Lachenmeier \& Sohnius, 2008), acetaldehyde in the Asian spirits should nevertheless be reduced to levels as low as technologically possible.

\section{Limitations}

Our sample is based on products exported to third countries and clearly is not representative for any of the countries. We therefore cannot currently provide the population-based exposure scenarios needed for quantitative risk assessments for the two aldehydes. We hope that our study might stimulate research activity into alcohol quality in Asia.

\section{References}

Baan, R., Grosse, Y., Straif, K., Secretan, B., El Ghissassi, F., Bouvard, V. . . . Cogliano, V. (2009). A review of human carcinogens - Part F: Chemical agents and related occupations. Lancet Oncology, 10, 1143-1144.

Feron, V. J., Til, H. P., de Vrijer, F., Woutersen, R. A., Cassee, F. R., \& van Bladeren, P. J. (1991). Aldehydes: Occurrence, carcinogenic potential, mechanism of action, and risk assessment. Mutatation Research, 259, 363-385.

Jendral, J. A., Monakhova, Y. B., \& Lachenmeier, D. W. (2011). Formaldehyde in alcoholic beverages: Large chemical survey using purpald screening followed by chromotropic acid spectrophotometry with multivariate curve resolution. International Journal of Analytical Chemistry, 2011, Article ID 797604, 11 pages, 2011. doi:10.1155/2011/797604

Kanteres, F., Rehm, J., \& Lachenmeier, D. W. (2009). Artisanal alcohol production in Mayan Guatemala: Chemical safety evaluation with special regard to acetaldehyde contaminaton. Science of the Total Environment, 407, 5861-5868.

Lachenmeier, D. W., Anh, P. T. H., Popova, S., \& Rehm, J. (2009). The quality of alcohol products in Vietnam and its implications for public health. International Journal of Environmental Research and Public Health, 6, 2090-2101.

Lachenmeier, D. W. \& Monakhova, Y. B. (2011). Shortterm salivary acetaldehyde increase due to direct exposure to alcoholic beverages as an additional cancer risk factor beyond ethanol metabolism. Journal of Experimental and Clinical Cancer Research, 30, 3. doi: 10.1186/1756-9966-30-3

Lachenmeier, D. W., Schoeberl, K., Kanteres, F., Kuballa, T., Sohnius, E. -M., \& Rehm, J. (2011). Is contaminated unrecorded alcohol a health problem in the European Union? A review of existing and methodological outline for future studies. Addiction, 106, 20-30.

Lachenmeier, D. W. \& Sohnius, E. -M. (2008). The role of acetaldehyde outside ethanol metabolism in the carcinogenicity of alcoholic beverages: Evidence from a large chemical survey. Food and Chemical Toxicology, 46, 2903-2911.

Liu, S. Q. \& Pilone, G. J. (2000). An overview of formation and roles of acetaldehyde in winemaking with emphasis on microbiological implications. 
International Journal of Food Science and Technology, 35, 49-61.

Rehm, J., Mathers, C., Popova, S., Thavorncharoensap, M., Teerawattananon, Y., \& Patra, J. (2009). Global burden of disease and injury and economic cost attributable to alcohol use and alcohol-use disorders. The Lancet, 373, 2223-2233.

Secretan, B., Straif, K., Baan, R., Grosse, Y., El Ghissassi, F., Bouvard, V. . . \& \& Cogliano, V. (2009). A review of human carcinogens - Part E: Tobacco, areca nut, alcohol, coal smoke, and salted fish. Lancet Oncology, 10, 1033-1034.

United States Environmental Protection Agency (US EPA) (1998). Formaldehyde (CASRN 50-00-0). Integrated Risk Information System. Document 0419. Washington, DC, United States: Author.

World Health Organization (WHO) (2012). Global Information System on Alcohol and Health (GISAH). Geneva, Switzerland: Author. www.who.int/ globalatlas/default.asp (Accessed 2011-05-23).

World Health Organization (WHO) (2011). Global status report on alcohol and health. Geneva, Switzerland: Author.

World Health Organization International Program on Chemical Safety (WHO IPCS) (2002). Formaldehyde. Concise international chemical assessment. Document 40. Geneva, Switzerland: Author. 